\title{
Chikungunya Virus Interacts with Heat Shock Cognate 70 Protein to Facilitate Its Entry into Mosquito Cell Line
}

\author{
Ayushman Ghosh ${ }^{\mathrm{a}} \quad$ Anita Desai $^{\mathrm{a}}$ Vasanthapuram Ravi ${ }^{\mathrm{a}}$ \\ Gayathri Narayanappa $^{b}$ Brij Kishore Tyagi ${ }^{c}$ \\ aDepartment of Neurovirology, National Institute of Mental Health and Neurosciences, Bangalore, India; \\ ${ }^{b}$ Department of Neuropathology, National Institute of Mental Health and Neurosciences, Bangalore, India; \\ ${ }^{c}$ Centre for Research in Medical Entomology, Madurai, India
}

\section{Keywords \\ Chikungunya · Aedes albopictus · C6/36 cells - Receptor/ interacting proteins $\cdot$ Heat shock cognate 70}

\begin{abstract}
Aim: The study was designed to identify putative Chikungunya virus (CHIKV) receptor/s on C6/36 cells that facilitate viral entry. Methods: The virus overlay protein binding assay (VOPBA) was adopted to identify CHIKV-interacting bands present in C6/36 cell membrane and identity of the protein was established by mass spectrometry. The role of this protein as a putative CHIKV receptor on C6/36 cells was confirmed by infection inhibition assay. Cell surface localization of the identified protein was studied by indirect immunofluorescence assay (IFA) on nonpermeabilized cells and by flow cytometry. Interaction between this protein and CHIKV was confirmed by co-immunoprecipation (Co-IP) and Western blotting. The effect of depletion of the identified protein by quercetin was demonstrated by infection inhibition assay. Results: A 70-kDa protein was identified as a CHIKV-interacting protein by VOPBA. MALDI-TOF analysis followed
\end{abstract}

\section{KARGER}

(c) 2018 S. Karger AG, Basel

E-Mail karger@karger.com

www.karger.com/int by homology search revealed that this protein could be heat shock cognate 70 (HSC 70). Anti-HSC 70 antibodies blocked CHIKV entry into $\mathrm{C} 6 / 36$ cells in a dose-dependent manner. IFA and flow cytometry analysis demonstrated HSC 70 localization on C6/36 cell surface. Co-IP experiments confirmed the interaction between HSC 70 and CHIKV envelope. Quercetin- and YM-01-treated C6/36 cells exhibited dose-dependent infection inhibition. Conclusion: HSC 70 serves as a putative $\mathrm{CHIKV}$ receptor on $\mathrm{C} 6 / 36$ cells.

(c) 2018 S. Karger AG, Basel

\section{Introduction}

Virus attachment/adsorption to host cells is a dynamic multistep event. The cell entry pathways for viruses are fundamentally defined by interactions between the viruses and their receptors at the cell surface. These interactions regulate mechanisms of virus attachment, uptake, and ultimately, penetration into the cytosol. Identification of receptors on host cells that are exploited by viruses for entry, and subsequently initiating infection, has 
garnered significant attention due to their importance as a determinant of the host range, tissue tropism, and virulence of a virus [1]. Viruses may utilize multiple host cell surface attachment factors (receptors) sequentially, or in a cell-type-specific manner to enter permissive cells; coreceptors may also be involved [2]. While some viruses exploit a phylogenetically conserved receptor, other viruses have been reported to attach to multiple receptors on different cell types $[2,3]$.

Identification of receptors have been an exciting arena in the context of Alphaviruses since the members of this group exhibit an enormous host range comprising both invertebrate and vertebrate hosts [1]. Chikungunya virus (CHIKV), an Old World alphavirus (Family Togaviridae, genus Alphavirus, species Chikungunya virus), is the causative agent of chikungunya disease. A number of chikungunya epidemics have been reported since the first documented 1952-1953 CHIKV outbreak in East Africa and Austral Africa (Tanzania, Uganda, and Zimbabwe) [4], resulting in widespread dissemination of the virus globally [5]. The disease is characterized by abrupt onset of high fever, headache, back pain, myalgia, and intense polyarthralgia, mainly affecting the extremities (ankles, wrists, and phalanges) and also large joints [6].

CHIKV is a small (about $60-70 \mathrm{~nm}$ in diameter), spherical, enveloped, single, positive-stranded RNA virus containing 11,805 nucleotides [7]. The genome comprises two open reading frames encoding nonstructural (nsP1, nsP2, nsP3, nsP4) and structural (C, E3, E2, 6k, E1) polyproteins. CHIKV glycoproteins E1 and E2, which are the main antigenic determinants and form an icosahedral shell at the virion surface, also mediate the invasion of susceptible cells. CHIKV is known to enter the host cell by receptor-mediated endocytosis [8]. The $50-\mathrm{kDa}$ E2 glycoprotein of CHIKV, a type I transmembrane glycoprotein, is responsible for binding host cell surface receptors, while the E1 glycoprotein is a class II fusion protein that mediates fusion of the viral and host cell membranes during virus entry $[9,10]$. Apart from a few reports, the entire repertoire of host cell surface molecules that CHIKV employs as receptor/s has not been completely delineated. Prohibitin has been identified as a CHIKV receptor on human microglial cells (CHME-5) [11]. ATP synthase $\beta$ subunit (ATPS $\beta$ ) was found to be involved in CHIKV entry into C6/36 cells, suggesting a conserved virus-arthropod interaction [12]. Our study was designed to identify the CHIKV-interacting proteins on C6/36 cells and to ascertain the role of the interacting protein $/ \mathrm{s}$ as putative CHIKV receptor/s by performing a series of experiments including infection inhibition assays.

\section{Materials and Methods}

Growth of Cells and Propagation of CHIKV in Tissue Culture CHIKV strain DRDE-06 (GenBank accession number: EF210157.2), which does not contain the A226V mutation in the E1 gene, was used in this study [13]. CHIKV was propagated in Vero cells grown in Dulbecco's modified Eagle's media (DMEM) (Gibco, USA). The titer of the CHIKV stock grown in Vero cells was established to be $10^{7} \mathrm{PFU} / \mathrm{mL}$. C6/36 cells were grown in Mitsuhashi and Maramorosch (M\&M) insect media (HiMedia Labs, India). The complete growth media consisted of basal medium supplemented with $10 \%$ fetal bovine serum (FBS) (Sigma-Aldrich, USA). Mammalian cell lines were allowed to grow at $37^{\circ} \mathrm{C}$ in a $5 \%$ $\mathrm{CO}_{2}$ incubator whereas the mosquito cell line $\mathrm{C} 6 / 36$ was incubated at $27^{\circ} \mathrm{C}$.

\section{Infection of C6/36 Cells with CHIKV}

Briefly, C6/36 cells $\left(0.05 \times 10^{6}\right.$ cells $\left./ \mathrm{mL}\right)$ were seeded on sterile coverslips in 24-well tissue culture plates and allowed to grow overnight until they reached $80 \%$ confluence. Cells were then infected with CHIKV at a multiplicity of infection (MOI) of 1 . The virus was allowed to adsorb on to the cells for $45 \mathrm{~min}$ at room temperature with gentle rocking. The inoculum was then withdrawn and basal media with 5\% FBS was added. Tissue culture plates were incubated for $48 \mathrm{~h}$ and examined under microscope at regular intervals post-infection (PI) to observe virus-induced cytopathic effects.

\section{Indirect Immunofluorescence Assay}

CHIKV infection of C6/36 cells was confirmed by indirect immunofluorescence assay (IFA). Infected cells were fixed using $4 \%$ paraformaldehyde and coverslips were then washed twice with sterile phosphate-buffered saline (PBS). Permeabilization was carried out using $0.3 \%$ Triton $\mathrm{X}-100$ for $10 \mathrm{~min}$ at $4{ }^{\circ} \mathrm{C}$, followed by blocking with $5 \%$ skimmed milk powder for $30 \mathrm{~min}$ at room temperature. Primary incubation was performed with anti-eastern equine encephalitis virus monoclonal antibody (Cat. No. MAB8754; Chemicon International, USA) for $2 \mathrm{~h}$ followed by incubation with FITC-tagged secondary conjugate (Cat. No. 621120380011730; GeNei, Merck, India) for $1 \mathrm{~h}$ at room temperature in a humid chamber. Anti-eastern equine encephalitis monoclonal antibody exhibits cross-reactivity to the CHIKV envelope region [14]. Coverslips were thoroughly washed with PBS, mounted in buffered glycerol saline on clean glass slides, and observed under a fluorescent microscope (Eclipse TS 100; Nikon, Japan). Uninfected cells were included as control.

\section{Membrane Protein Preparation and Virus Overlay Protein}

Binding Assay

The cell membrane proteins of $\mathrm{C} 6 / 36$ were prepared as described earlier $[15,16]$. Briefly, monolayers of C6/36 cells were detached by $5 \mathrm{~mm}$ EDTA solution ( $\mathrm{pH}$ 7.4). Cells were pelleted down by centrifugation at 3,000 rpm for $10 \mathrm{~min}$. The supernatant was discarded and the cell pellet was incubated with buffer $\mathrm{M}$ (100 $\mathrm{mM} \mathrm{NaCl}, 20 \mathrm{mM}$, Tris base [pH 8], $2 \mathrm{mM} \mathrm{MgCl}_{2} 1 \mathrm{mM}$ EDTA and $1 \mathrm{~mm} \beta$-mercaptoethanol) for $20 \mathrm{~min}$ on ice. The cells were disrupted by $5-6$ clean strokes in a Dounce homogenizer. The suspension was centrifuged at $2,500 \mathrm{rpm}$ for $20 \mathrm{~min}$ at $4{ }^{\circ} \mathrm{C}$. The clear supernatant was collected and centrifuged at $18,000 \mathrm{rpm}$ for 30 $\min$ at $4^{\circ} \mathrm{C}$. The supernatant was discarded and the pellet contain- 
ing cell membrane proteins was dissolved in buffer $M$ without $\beta$-mercaptoethanol. The concentration of membrane proteins thus obtained was estimated using a spectrophotometer (NanoDrop 2000/2000c; Thermo Scientific, USA).

The purified C6/36 cell membrane proteins (50 $\mu \mathrm{g} /$ well) were subjected to sodium-dodecyl sulfate-10\% polyacrylamide gel electrophoresis (40 W constant) (SDS-PAGE) followed by Western blotting (100 mA constant) onto a nitrocellulose membrane (BioRad, USA). Following overnight blocking using 5\% skimmed milk powder, the membrane was washed thrice ( 5 min each) with PBS containing $0.05 \%$ Tween 20 (PBST) and incubated with infectious $\mathrm{CHIKV}$ cell culture supernatant (titer $10^{7} \mathrm{PFU} / \mathrm{mL}$ ) for $3 \mathrm{~h}$ at room temperature with gentle rocking. The membrane was again washed thrice and incubated with 1:100 dilution of anti-CHIKV polyclonal antibody (Cat. No. 04-0008; IBT Bioservices, USA) for $2 \mathrm{~h}$ at room temperature. Following another round of washing with PBST, secondary incubation was carried out with anti-rabbit biotinylated antibody (Cat. No. AP182B; Millipore, USA) for $1 \mathrm{~h}$ at room temperature. The membrane was further incubated with streptavidin peroxidase conjugate for $45 \mathrm{~min}$ at room temperature and washed thoroughly with PBST. The cell membrane protein/(s) interacting with CHIKV was detected by chemiluminescence using a commercial kit following the manufacturer's instructions (Thermo Scientific).

\section{MALDI-TOF/-LC-MS Analysis}

The virus overlay protein binding assay (VOPBA) membrane and the SDS-10\% PAGE of C6/36 cells were aligned and the region in the gel corresponding to the positive band/s in the VOPBA was excised and processed for MALDI-TOF (matrix-assisted laser desorption ionization - time of flight). C6/36 gel band was submitted to the Centre for Cellular and Molecular Platforms (C-CAMP), Bangalore, for mass spectrometry analysis following the standard protocol [17]. The generated data was searched for the identity of the peptides on the Mascot search engine using the SwissProt database.

\section{Infection Inhibition Assay to Ascertain the Role of Cell Surface}

Proteins by IFA

To ascertain the role of heat shock cognate 70 (HSC 70) protein in CHIKV entry into C6/36 cells, a "dose-dependent infection inhibition" assay was designed using monoclonal antibody against HSC 70 . C6/36 cells $\left(0.05 \times 10^{6}\right.$ cells $\left./ \mathrm{mL}\right)$ grown on coverslips in 24 -well tissue culture plates were pre-treated with two concentrations (1:50 and 1:100) of anti-HSC 70 monoclonal antibody (Cat. No. MA3-014; ThermoFisher Scientific, USA) for $3 \mathrm{~h}$. Anti-actin antibody (1:100) (Cat. No. A2066; Sigma-Aldrich) was used as control. Cells were washed with sterile media and infected with $\mathrm{CHIKV}$ at MOI of 1 for $1 \mathrm{~h}$ in a $27^{\circ} \mathrm{C}$ incubator. The virus was withdrawn and the cells were replenished with fresh medium. After $48 \mathrm{~h}$, the cells were fixed with $4 \%$ paraformaldehyde and stained for the presence of CHIKV antigen by IFA as described earlier.

\section{Infection Inhibition Assay to Ascertain the Role of Cell Surface} Proteins by Plaque Reduction Assay

In order to confirm observations obtained in the IFA using anti-HSC 70 monoclonal antibody, a virus yield reduction assay was carried out. Suspension cultures of C6/36 were incubated in triplicate with (i) anti-HSC 70 antibody (1:50 and 1:100), (ii) antiactin antibody (nonspecific antibody control), or (iii) PBS (virus control) for $2 \mathrm{~h}$ at $27^{\circ} \mathrm{C}$ with intermittent rocking. Subsequently, MOI of $1 \mathrm{CHIKV}$ was added to all the tubes which were further incubated for $2 \mathrm{~h}$ at $27^{\circ} \mathrm{C}$ with intermittent swirling. Cells were then pelleted down by centrifugation at 2,500 rpm for $15 \mathrm{~min}$ at $4^{\circ} \mathrm{C}$. The supernatant was discarded; cells were resuspended in 1 $\mathrm{mL}$ media containing $10 \% \mathrm{FBS}$, plated onto coverslips in a 24 -well plate and allowed to grow for $48 \mathrm{~h}$. Cells were subjected to three freeze-thaw cycles to release the cell-bound virus. This cell culture fluid was used to perform the plaque assay using Vero cells to enumerate viral particles.

\section{Co-Immunoprecipitation and Western Blot Analysis}

The co-immunoprecipitation (Co-IP) assay was performed following a protocol described earlier [15]. C6/36 membrane protein $(150 \mu \mathrm{g})$ was incubated with CHIKV suspension. The proteins were allowed to interact for $2 \mathrm{~h}$ on a rocker at $4^{\circ} \mathrm{C}$ in the presence of $2 \times$ IP buffer ( $2 \%$ Triton X-100, $0.1 \%$ NP 40 ). Next, the complex was incubated with anti-HSC 70 antibody overnight at $4{ }^{\circ} \mathrm{C}$. This immune complex was separated by reacting with Protein $\mathrm{G}$ agarose beads (Santa Cruz Biotechnology, USA) for $2 \mathrm{~h}$ on a rocker at $4{ }^{\circ} \mathrm{C}$. After washing the beads thrice with $1 \times$ IP buffer, bound proteins were eluted using RIPA buffer (25 mM Tris, $150 \mathrm{~mm} \mathrm{NaCl}$, $0.1 \%$ SDS, $0.5 \%$ sodium deoxycholate, $1 \%$ NP 40, PMSF), resolved by $10 \%$ SDS-PAGE, and Western blotted on nitrocellulose membrane. The presence of CHIKV E protein and HSC 70 in the HSC 70-CHIKV complex was detected using anti-CHIKV antibody and anti-HSC 70 antibodies. The signal was detected by chemiluminescence.

Additionally, the immune complex formed by C6/36 membrane protein-CHIKV was incubated with anti-CHIKV antibodies and subsequently separated using Protein G agarose beads. After washing, the proteins were eluted, resolved by $10 \%$ SDS-PAGE, and a Western blot was performed. The presence of HSC 70 and CHIKV E protein in the complex was detected by probing with anti-HSC 70 and anti-CHIKV antibodies. Normal rabbit serum was used as control.

\section{Surface Expression of CHIKV-Interacting Protein/s on C6/36 Cells}

To detect the cellular localization of HSC70 in C6/36 cells, Western blot analysis was carried out. The cell membrane and cytoplasmic extracts were resolved on SDS-10\% PAGE followed by Western blot analysis using anti-HSC 70 antibody as described above. The membrane and cytosolic fractions used were assessed by Western blot for relative purity using antibodies to GAPDH (Cat. No. PA1-987; ThermoFisher Scientific) which is abundant in the cytosolic fraction compared to the membrane fraction. Additionally, IFA was performed on C6/36 cells to reconfirm the distribution of membrane and cytoplasmic HSC 70 protein. Briefly, $\mathrm{C} 6 / 36$ cells were seeded at a density of $10^{5}$ cells/well in a 24 -well plate at $27^{\circ} \mathrm{C}$ in triplicate. After $24 \mathrm{~h}$, the cells were fixed using $4 \%$ paraformaldehyde at room temperature. The cells in one well were permeabilized using chilled $0.5 \%$ Triton X-100 while the other set was not permeabilized. IFA was performed using anti-HSC 70 antibody followed by FITC as mentioned earlier. Anti-CHIKV antibody was used as negative control.

\section{Flow Cytometry Analysis}

C6/36 cells were seeded at a density of $0.5 \times 10^{6}$ per $\mathrm{mL}$ and grown overnight in T-25 flasks. CHIKV infection of cells at MOI 


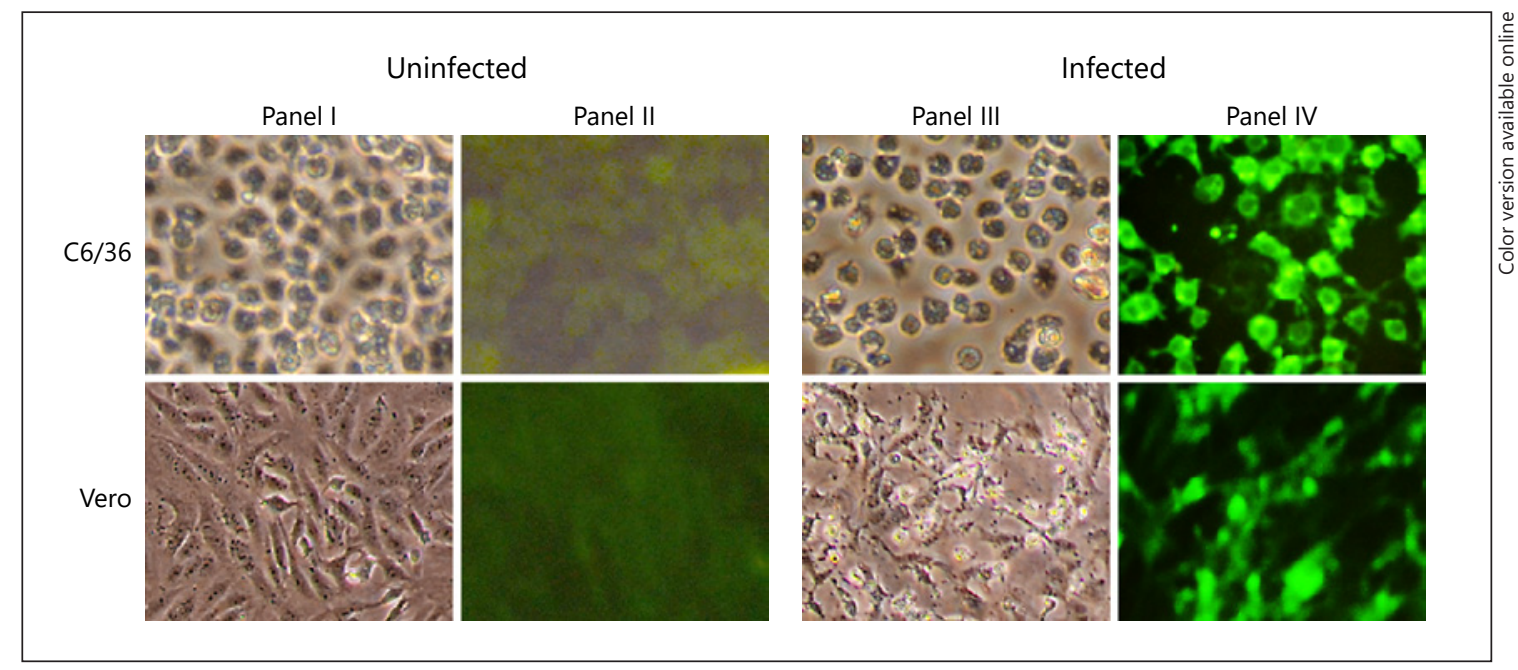

Fig. 1. Infection of cell lines with CHIKV. Panels I and III represent bright field phase contrast microscopic images whereas II and IV represent fluorescent images. Cells were infected with CHIKV (multiplicity of infection of 1) for $30 \mathrm{~h}$. Note the cytopathic effects induced by CHIKV in Vero cells. Bright fluorescence observed in C6/36 and Vero cells indicates the presence of CHIKV antigen in infected cells which is absent in uninfected cells.

of 1 was carried out as mentioned previously for 24,48 , and $72 \mathrm{~h}$ PI. Uninfected cells were used as control. After infection, cells were harvested and incubated with 1:750 dilution of anti-HSC 70 monoclonal antibody at $4{ }^{\circ} \mathrm{C}$ for $45 \mathrm{~min}$. Cells were counterstained with FITC-conjugated secondary antibody (Cat. No. 621120380011730; GeNei, Merck), fixed with $2 \%$ paraformaldehyde ( $\mathrm{pH} 7.4$ ), and analyzed for fluorescence using a cytofluorometer (FACS Aria; Becton-Dickinson Biosciences, USA). Flow cytometry results were analyzed using Flowjo software (Tree Star Inc., USA).

\section{Depletion of HSC 70 Using Quercetin in C6/36 Cells}

A stock solution of quercetin (1 mM) (Cat. No. Q0125; SigmaAldrich) was prepared in $0.2 \%$ dimethyl sulfoxide (DMSO). The stock was diluted using M\&M medium. Concentrations of 100 and $50 \mu \mathrm{M}$ quercetin were selected based on earlier studies and tested on $\mathrm{C6} / 36$ cells to ensure that there was no toxicity and the cell viability was not compromised [15].

Monolayers of C6/36 cells were grown on coverslips in a 24well plate as described previously. Cell monolayers were treated with concentrations of 100 and $50 \mu \mathrm{M}$ quercetin for $6 \mathrm{~h}$ at $27^{\circ} \mathrm{C}$. After incubation, quercetin was withdrawn and the cells were washed twice with plain medium. One set of quercetin-treated cells and untreated cells were infected with CHIKV at MOI of 1. Another set of quercetin-treated cells and untreated cells were used as controls. Infectious cell supernatant was harvested after $48 \mathrm{~h}$ and the plaque assay was performed to check virus yield.

\section{Depletion of HSC 70 Using YM-01 in C6/36 Cells}

A stock solution of YM-01 (10 $\mu$ M) (Cat. No. SML0943; SigmaAldrich) was prepared which was further diluted using M\&M medium. Concentrations of $0.25,0.50,0.75$ and $1 \mu \mathrm{M}$ YM-01 were selected based on earlier studies and tested on C6/36 cells to ensure that there was no toxicity and the cell viability was not compromised [18].
Monolayers of C6/36 cells were grown on coverslips in a 24-well plate and treated with different concentrations of YM-01 for $6 \mathrm{~h}$ at $27^{\circ} \mathrm{C}$. After incubation, YM-01 was withdrawn and the cells were washed twice with plain medium. One set of YM-01-treated cells and untreated cells were infected with CHIKV at MOI of 1. Another set of YM-01-treated cells and untreated cells were used as controls. The virus was withdrawn and the cells were replenished with fresh medium. After $48 \mathrm{~h}$, the cells were fixed with $4 \%$ paraformaldehyde and stained for the presence of CHIKV antigen by IFA as described earlier. Additionally, infectious cell supernatant was also harvested and the plaque assay was performed to check virus yield.

\section{Results}

\section{Indirect Immunofluorescence Assay to Confirm}

CHIKV Infection of Cell Lines

$\mathrm{CHIKV}$-induced cytopathic effects, characterized by loss of cell morphology leading to disruption of cell monolayers, were observed only in infected Vero cells. The presence of apple green fluorescence in infected C6/36 and Vero cells confirmed CHIKV infection (Fig. 1).

\section{VOPBA to Identify Surface Molecules on C6/36 Cells That Interact with CHIKV}

To identify proteins present on C6/36 cell surface that interact with CHIKV envelope protein, VOPBA followed by MALDI-TOF analysis was carried out. As evident from Figure 2, a distinct band of an approximate molecular mass of $70 \mathrm{kDa}$ was identified in the cell membrane 
Fig. 2. Virus overlay protein binding assay (VOPBA) with C6/36 cellular fraction proteins. Membrane and cytosolic proteins from C6/36 cells were resolved by SDSPAGE and transferred to nitrocellulose membrane. Infectious CHIKV suspension was overlaid on the nitrocellulose membrane. The interacting proteins were detected by using CHIKV-specific polyclonal antibody. a Coomassie stained gel containing resolved $\mathrm{C} 6 / 36$ proteins. Lane $\mathrm{M}$ indicates the molecular weight marker. Lane CMF consists of cell membrane protein fraction. Lane CYF consists of cytosolic protein fraction. b VOPBA of C6/36 cellular membrane protein blots. Note $\sim 70-\mathrm{kDa}$ protein (arrow) staining positive with $\mathrm{CHIKV}$ polyclonal antibodies in lane CMF but not in CYF lane. Lane $\mathrm{M}$ indicates the molecular weight marker. Lane CMF consists of cell membrane protein fraction. Lane CYF consists cytosolic protein fraction.

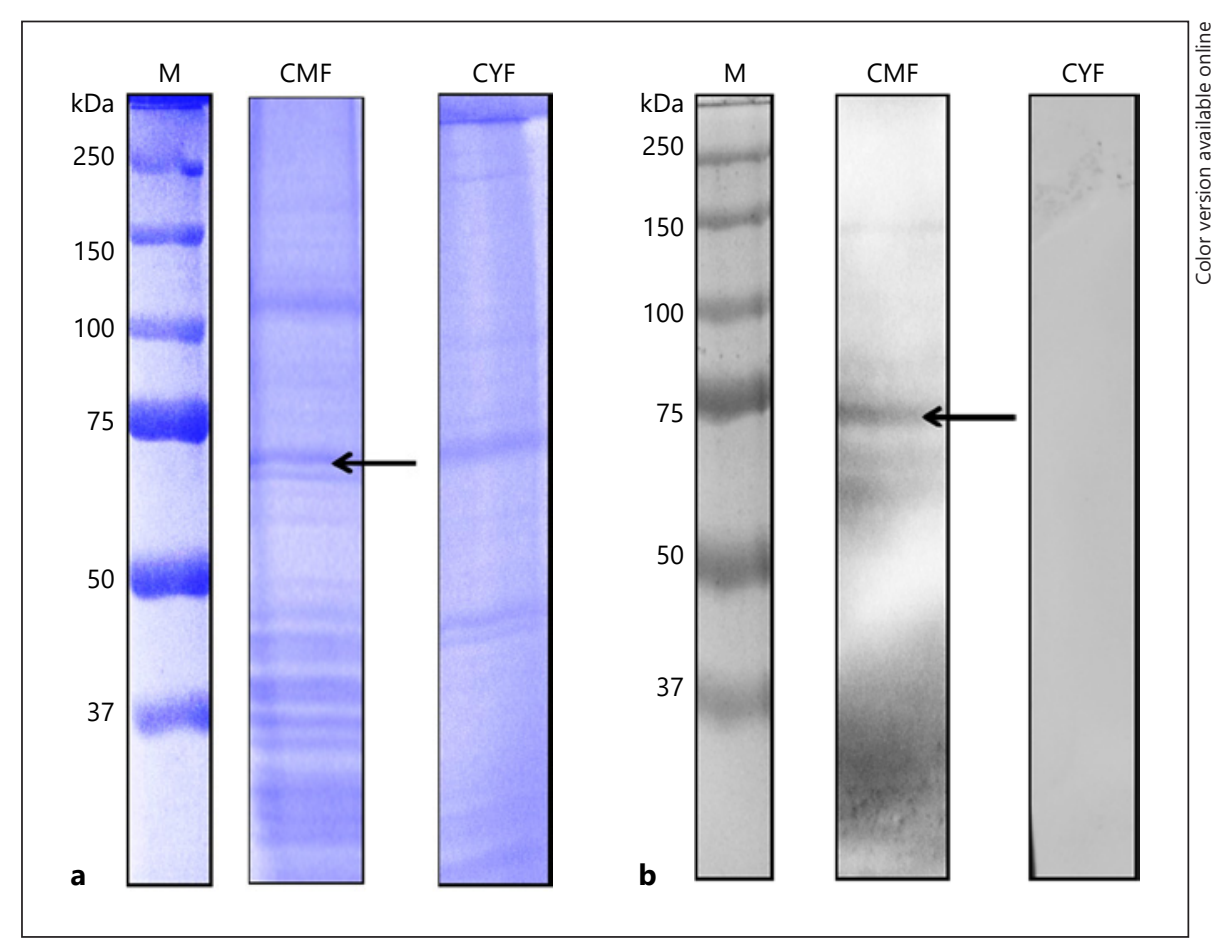

Table 1. Results of Mascot search of peak lists generated from MS/MS analysis of CHIKV binding protein on C6/36 cell membrane using the SwissProt database

\begin{tabular}{|c|c|c|c|c|c|c|c|}
\hline $\begin{array}{l}\text { Accession } \\
\text { No. }\end{array}$ & Description & Score & Coverage & $\begin{array}{l}\text { Unique } \\
\text { peptides }\end{array}$ & $\begin{array}{l}\text { Peptides, } \\
n\end{array}$ & PSM & $\begin{array}{l}\mathrm{MW} \\
\mathrm{kDa}\end{array}$ \\
\hline 604782137 & $\begin{array}{l}\text { putative 2-oxoglutarate dehydrogenase E1 subunit } \\
\text { (Aedes albopictus) }\end{array}$ & 943.51 & 25.12 & 21 & 21 & 24 & 119.14 \\
\hline 604781392 & putative heat shock cognate 70 (Aedes albopictus) & 766.87 & 28.51 & 13 & 14 & 17 & 72.33 \\
\hline 604781534 & $\begin{array}{l}\text { putative endoplasmic reticulum glucose-regulated } \\
\text { protein grp94/endoplasmin, partial (Aedes albopictus) }\end{array}$ & 712.93 & 24.46 & 14 & 14 & 16 & 79.67 \\
\hline 604782078 & $\begin{array}{l}\text { putative GATA zinc finger domain containing } \\
\text { protein } 14 \text { species (Aedes albopictus) }\end{array}$ & 633.98 & 21.39 & 17 & 17 & 17 & 110.29 \\
\hline
\end{tabular}

Heat shock cognate 70 (HSC 70) protein (molecular mass: $72.32 \mathrm{kDa}$, homology score: 766.86 ) was identified as the most likely bona fide protein to serve as a CHIKV receptor on C6/36 cells. All the other proteins were not taken up for subsequent analysis as they did not fulfil the requirements of the algorithm (details provided in the text). PSM, peptide spectrum matches; MW, molecular weight.

protein fraction lane with membrane fractions of $\mathrm{C} 6 / 36$ cells. However, no CHIKV-interacting band/s was observed in the lane containing C6/36 cytoplasmic protein fractions (Fig. 2).

A $70-\mathrm{kDa}$ protein present in the membrane fraction of $\mathrm{C} 6 / 36$ cells was identified as a CHIKV-interacting protein. In order to establish the identity of this protein, the Coomassie stained gel containing C6/36 membrane pro- tein (Fig. 2) was aligned with the VOPBA membrane and the band corresponding to $\sim 70-\mathrm{kDa}$ protein was excised and processed for MALDI-TOF analysis. As evident from the figure, amidst the numerous proteins identified by SDS-PAGE in the crude C6/36 membrane protein fraction, only a single putative $\mathrm{CHIKV}$-interacting protein band was identified in the VOPBA membrane. Hence this band was further processed for identification. 
Fig. 3. Infection inhibition assay using anti-HSC 70 antibody - immunofluorescence study. C6/36 cells were infected with $\mathrm{CHIKV}$ in the absence and presence of different dilutions of anti-HSC 70 antibody (as indicated), a Phase contrast microscopic images. b Results obtained in the immunofluorescence assay. The CHIKV antigen was detected in the cells $48 \mathrm{~h}$ post-infection. Note the reduction of fluorescence staining for CHIKV antigen in the cells incubated with anti-HSC 70 antibodies (b III and IV) compared to controls (b II and V).
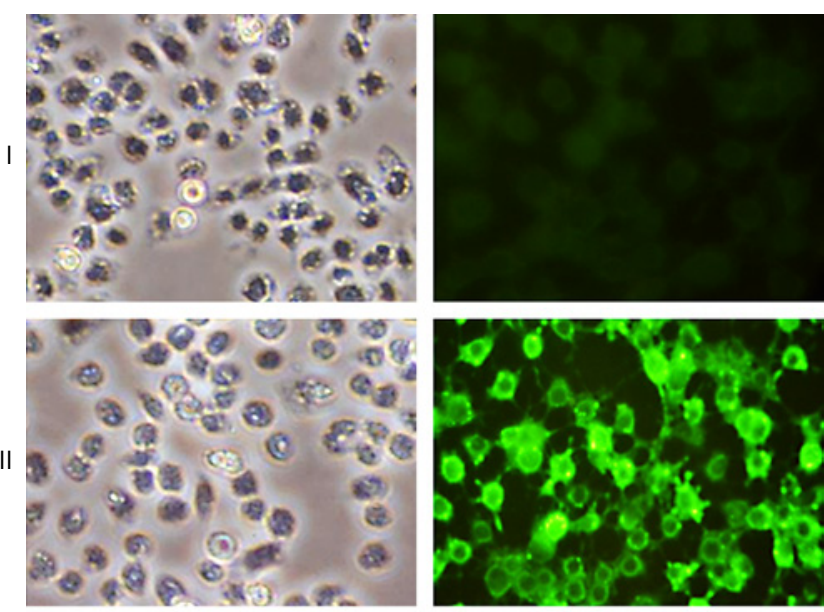

Mock
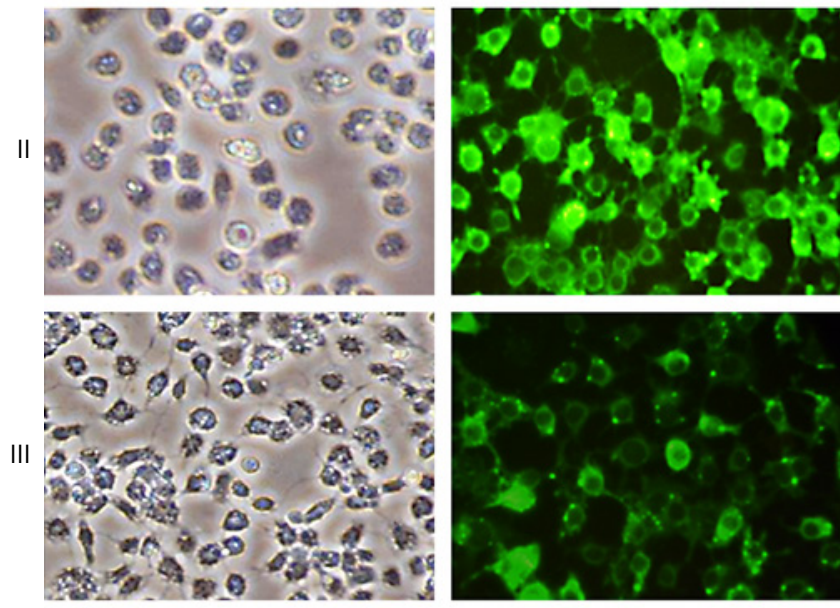

CHIKV

Control

Anti-HSC 70, 1:100

+ CHIKV

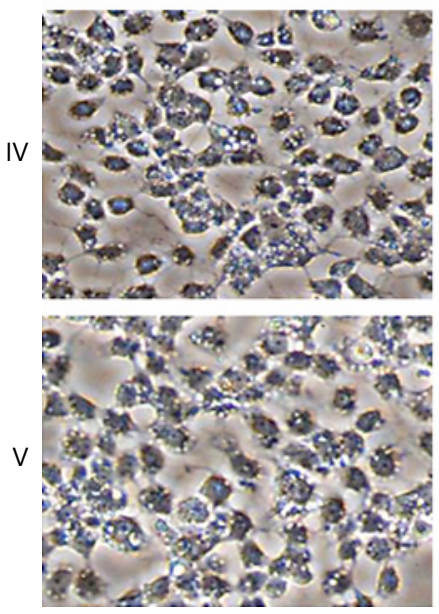

a

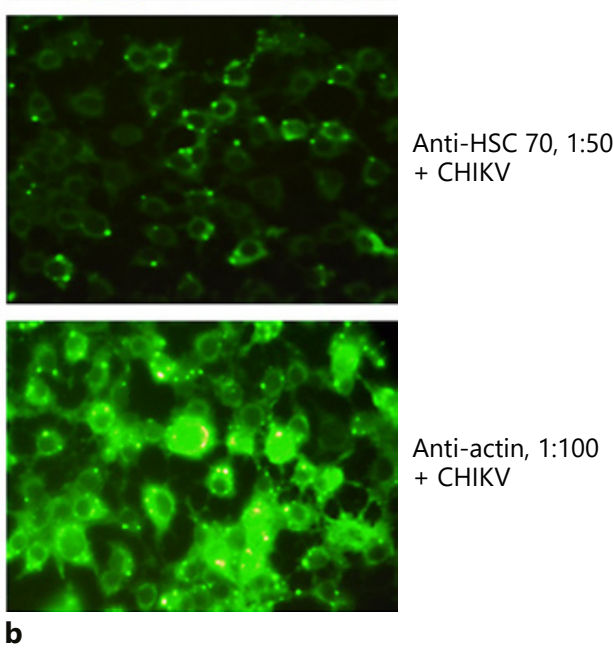

Mass Spectrometry and Mascot Analysis of C6/36

Proteins Interacting with CHIKV

The lists of proteins generated through LC-MS/MS (liquid chromatography - mass spectrometry/mass spectrometry) analysis of the tryptic digested protein product obtained on LC-MS/MS analysis are tabulated (Table 1). A homology search employing the Mascot search engine and the SwissProt protein database identified several probable proteins. An algorithmic approach was adopted to identify the most likely protein to serve as CHIKV re- ceptor on C6/36 cells. The list of proteins generated by the Mascot search was arranged in descending order of homology scores. Proteins which had more than ten unique peptides were filtered. The four proteins were found to be arranged in descending order of peptide spectrum matches. The filtered data was then manually inspected for the molecular weights, nature of the protein, likelihood of it being present on the cell membrane, and region of excision of the CHIKV-reacting C6/36 membrane protein band. Based on these criteria, HSC 70 protein (molecular 


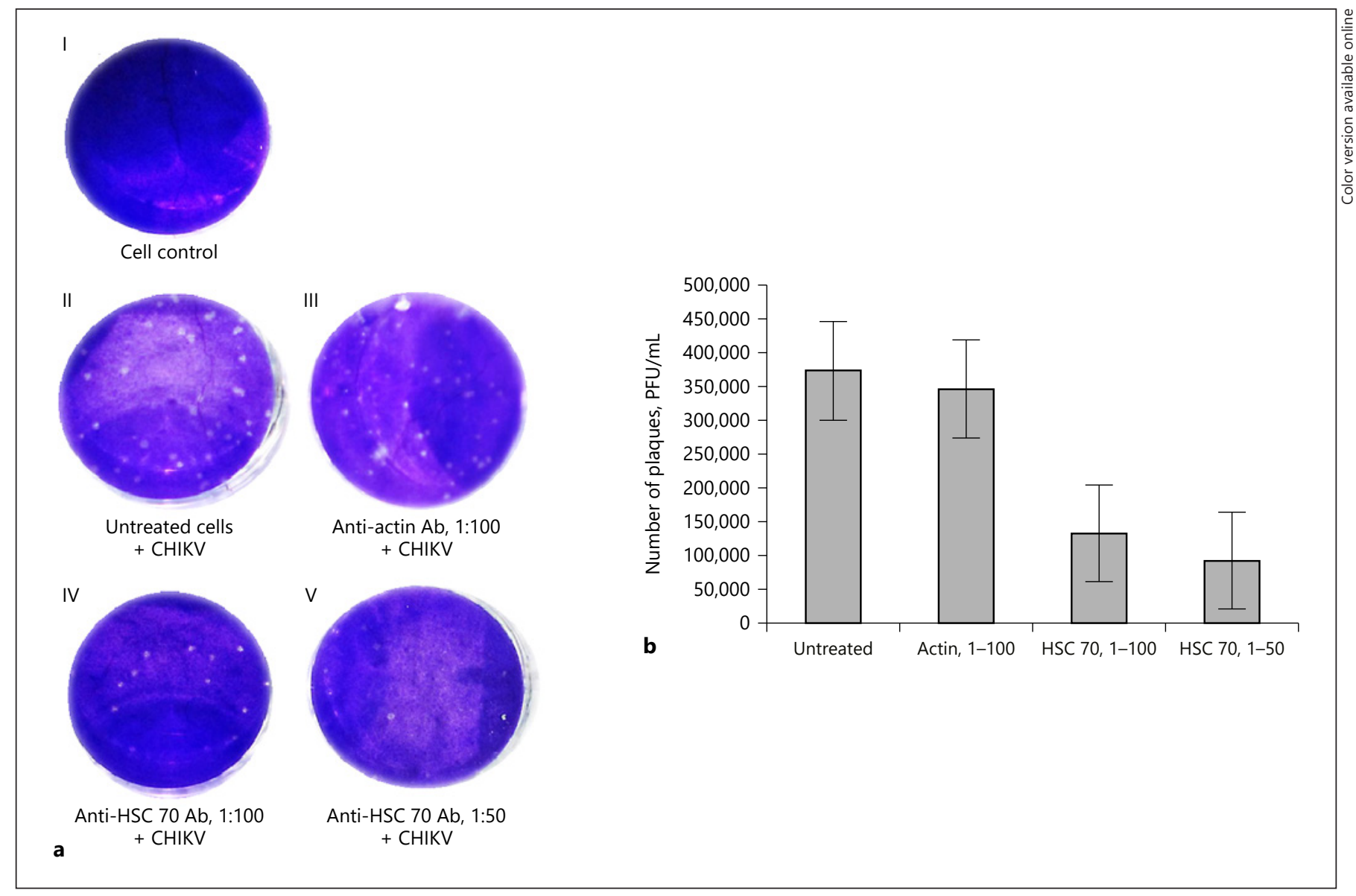

Fig. 4. Infection inhibition assay using anti-HSC 70 monoclonal antibody plaque reduction assay. C6/36 cells were incubated with different dilutions of anti-HSC 70 antibody (as indicated) followed by CHIKV infection. Plaque assay was carried out with the harvested supernatant post-infection. Untreated cells and cells treated

with anti-actin antibody served as controls. Note the marked reduction in plaques obtained in cells treated with anti-HSC 70 antibody (a). The mean results of plaque reduction obtained in triplicate experiments are represented graphically in $\mathbf{b}$.

mass: $72.32 \mathrm{kDa}$, homology score: 766.86 ) was identified as the most likely bona fide protein to serve as a CHIKV receptor on C6/36 cells (Table 1). All the other proteins were not taken up for subsequent analysis as they did not fulfil the requirements of the algorithm.

Immunofluorescence Assay with anti-HSC 70

Monoclonal Antibody Depicting Inhibition of CHIKV

Infection in C6/36 Cells

The "infection inhibition" immunofluorescent assay performed using monoclonal antibody to HSC 70 revealed that pre-incubation of C6/36 cells with increasing concentrations of anti-HSC 70 antibody inhibited viral infection in a dose-dependent manner (Fig. 3). On the other hand, C6/36 cells pre-incubated with anti-actin an-

tibody did not exhibit any decrease in infection compared to virus control.

Infection Inhibition by Plaque Reduction Assay Using Anti-HSC 70 Monoclonal Antibody

A virus yield reduction assay was performed to further demonstrate that anti-HSC 70 antibody inhibits CHIKV entry into $\mathrm{C6} / 36$ cells. The number of plaques obtained in the virus control was $3.73 \times 10^{5} \mathrm{PFU} / \mathrm{mL}$. On the other hand, a dose-dependent reduction of plaques was observed in C6/36 cells pre-incubated with anti-HSC 70 antibody. A significant reduction $(74.8 \%)$ of plaques was observed $\left(0.93 \times 10^{5} \mathrm{PFU} / \mathrm{mL}\right)$ when cells were pre-incubated with 1:50 dilution of anti-HSC antibody and a reduction of $64 \%$ in the number of plaques $\left(1.33 \times 10^{5} \mathrm{PFU} /\right.$ 


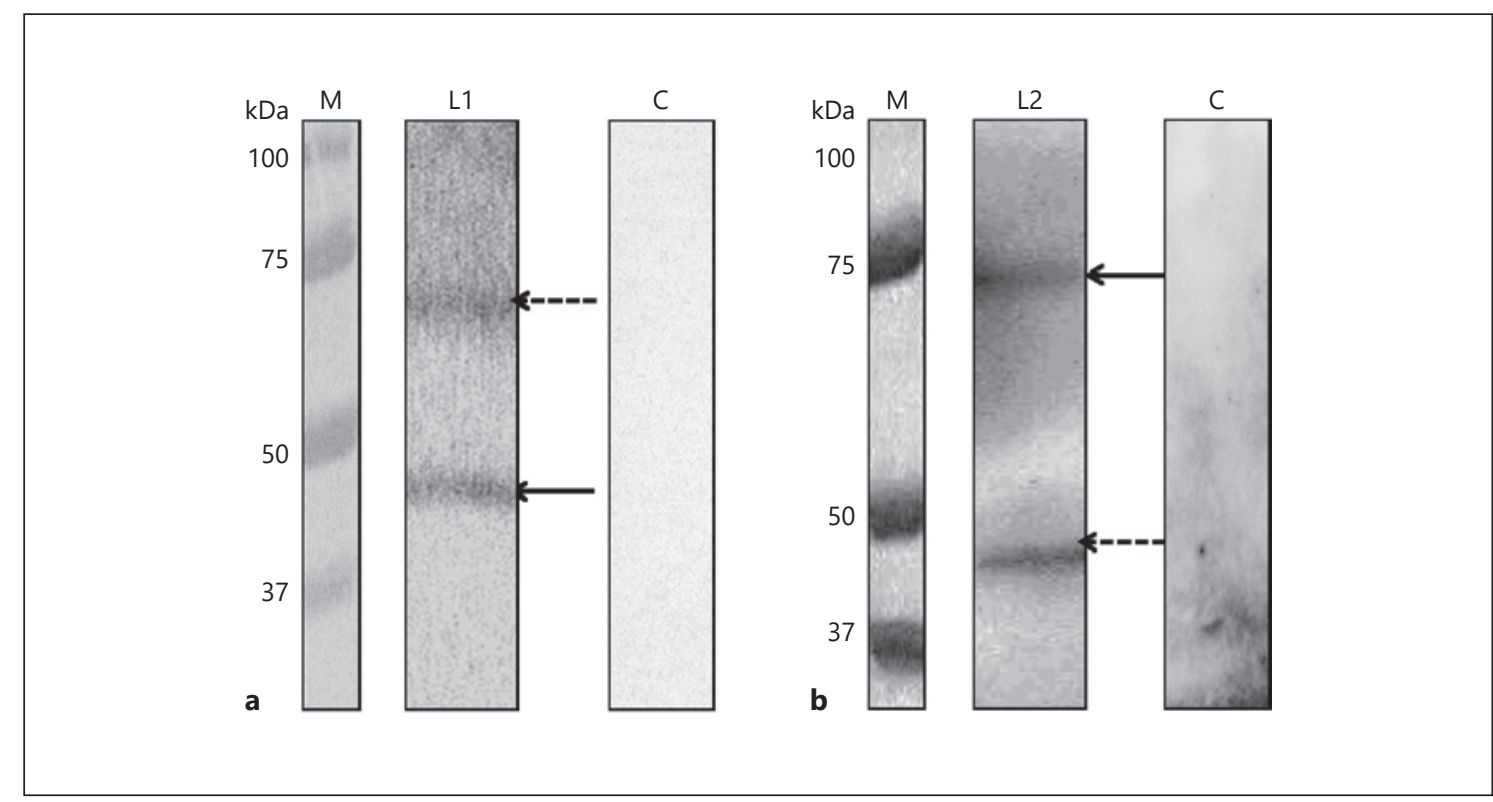

Fig. 5. Western Blot analysis following Co-IP experiment to demonstrate the interaction between HSC 70 and CHIKV protein. a Lane $\mathrm{M}$ represents the molecular weight marker. The immunoprecipitated complex (C6/36 membrane + CHIKV and incubated with anti-HSC 70 antibody) obtained after the pull-down assay was resolved in 10\% SDS-PAGE and transblotted. The presence of CHIKV E protein $(\sim 45 \mathrm{kDa}$, arrow) and HSC 70 protein $(\sim 70$ $\mathrm{kDa}$, dashed arrow) in the complex was confirmed by Western blot analysis using anti-CHIKV and anti-HSC 70 antibodies (L1). Lane

$\mathrm{mL}$ ) was observed upon pre-incubating C6/36 cells with 1:100 dilution of anti-HSC antibody (Fig. 4).

Co-IP Assay to Confirm that HSC 70 Present on C6/36 Cell Surface Interacts with CHIKV E Protein

Interaction between HSC 70 and CHIKV E protein was demonstrated by Co-IP experiments. The immunoprecipitated complex (C6/36 membrane $+\mathrm{CHIKV}$ and incubated with anti-HSC 70 antibody) obtained after the pull-down assay was resolved in 10\% SDS-PAGE and transblotted. The presence of both CHIKV E protein $(\sim 45 \mathrm{kDa})$ and HSC $70(\sim 70 \mathrm{kDa})$ in the complex was confirmed by Western blot analysis using the respective antibodies (Fig. 5).

Similarly, the immunoprecipitated complex (C6/36 membrane + CHIKV and incubated with anti-CHIKV antibody) obtained after the pull-down assay was resolved in 10\% SDS-PAGE and transblotted. The presence HSC 70 protein $(\sim 70 \mathrm{kDa})$ and CHIKV E protein $(\sim 45$ $\mathrm{kDa}$ ) in the complex was confirmed by Western blot analysis using the respective antibodies (Fig. 5).
$\mathrm{C}$ represents normal rabbit serum that was run as a control. b The immunoprecipitated complex (C6/36 membrane + CHIKV and incubated with anti-CHIKV antibody) obtained after the pulldown assay was resolved in $10 \%$ SDS-PAGE and transblotted. The presence HSC 70 protein $(\sim 70 \mathrm{kDa}$, arrow) and CHIKV E protein $(\sim 45 \mathrm{kDa}$, dashed arrow) in the complex was confirmed by Western blot analysis using anti-HSC 70 and anti-CHIKV antibodies (L2). Lane $\mathrm{C}$ represents normal rabbit serum that was run as a control.

\section{Demonstration of Surface Expression of HSC 70 on} C6/36 Cells Using Western Blot, Immunofluorescence Assay, and Flow Cytometry

The presence of HSC 70 on C6/36 membrane as well as in the cytoplasm was confirmed by Western blot analysis. A lone band corresponding to $\sim 70 \mathrm{kDa}$ was observed for the membrane fraction and cytoplasmic fraction of C6/36 cells (Fig. 6). The presence of HSC 70 on the surface of $\mathrm{C} 6 / 36$ cells was re-confirmed by performing indirect IFA with cells under permeabilized and nonpermeabilized conditions. Anti-CHIKV antibody was used as a negative control in the experiment. The results showed that HSC 70 was present both in the cytoplasm (permeabilized) as well as on the cell membrane (nonpermeabilized) of C6/36 cells (Fig. 7).

Flow cytometry analysis was performed on uninfected and CHIKV-infected C6/36 cells to determine the pattern of cell surface HSC 70 expression at 24, 48, and $72 \mathrm{~h}$ PI. The intrinsic background fluorescence (nonspecific) of the uninfected cells is shown in Figure 8. The results indicated that there is an increase in the HSC 70 protein 


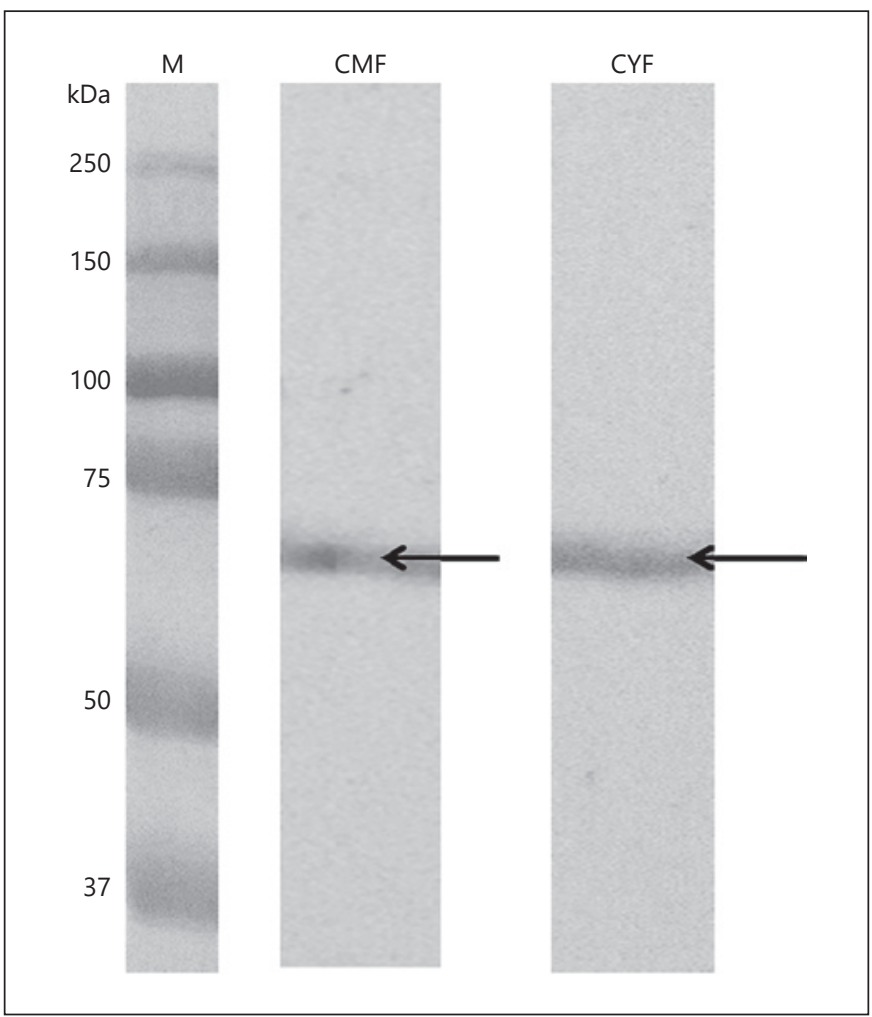

Fig. 6. Localization of HSC 70 on C6/36 cells by Western blot. Western blot analysis was performed to demonstrate the presence of HSC 70 on the membrane and cytosol. C6/36 cell membrane and cytosolic proteins were resolved on SDS-10\% PAGE, transblotted, and probed with anti-HSC 70 antibody. Lane M indicates the molecular weight marker. Lane CMF consists of cell membrane protein fraction. Lane CYF consists of cytosolic protein fraction. Note that HSC 70 is present in both the membrane and cytosolic fractions (arrows).

expression after $24 \mathrm{~h}$ PI and a drop in the expression level 48 h PI onwards (Fig. 8).

Quercetin Treatment Depletes HSC 70 on C6/36 Cell Surface Resulting in Reduced Virus Entry

Quercetin is a plant-derived flavonoid which is known to deplete heat shock protein 70 family members [19]. C6/36 cells were treated with 50 and $100 \mu \mathrm{M}$ of commercially procured quercetin as described earlier [15]. As evident from the IFA, near complete depletion of surface HSC 70 was observed in quercetin-treated cells compared to control (Fig. 9). Further, the plaque assay performed using cell supernatant of quercetin-treated C6/36 cells infected with CHIKV exhibited a significant reduction in the number of plaques compared to supernatant from cells infected with CHIKV but not treated with quercetin
(Fig. 9). The number of plaques obtained with untreated cells was $2.93 \times 10^{5} \mathrm{PFU} / \mathrm{mL}$. On the other hand, $40 \%$ reduction $\left(1.66 \times 10^{5} \mathrm{PFU} / \mathrm{mL}\right)$ and $76 \%$ reduction $(0.55 \times$ $10^{5} \mathrm{PFU} / \mathrm{mL}$ ) were observed when cells were treated with 50 and $100 \mu \mathrm{M}$ of quercetin, respectively (Fig. 9). This further confirms the role of HSC 70 as a putative CHIKV receptor in $\mathrm{C} 6 / 36$ cells.

\section{YM-01 Treatment of C6/36 Cells Inhibits HSC 70 \\ Resulting in Reduced CHIKV Infection}

YM-01 is a small molecule inhibitor of HSC $70[18$, 20]. C6/36 cells were treated with increasing concentrations $(0.25,0.50,0.75$, and $1 \mu \mathrm{M})$ of commercially procured YM-01. The "infection inhibition" immunofluorescent assay revealed that pre-incubation of C6/36 cells with increasing concentrations of YM-01 inhibited viral infection in a dose-dependent manner (Fig. 10). On the other hand, C6/36 cells pre-incubated with anti-actin antibody did not exhibit any decrease in infection compared to virus control. Further, the plaque assay performed using cell supernatant of YM-01-treated C6/36 cells infected with CHIKV exhibited a significant reduction in the number of plaques compared to supernatant from cells infected with CHIKV but not treated with YM-01 (Fig. 11). The number of plaques obtained with untreated cells was $4.03 \times 10^{5} \mathrm{PFU} / \mathrm{mL}$. On the other hand, $42 \%$ reduction $\left(2.4 \times 10^{5} \mathrm{PFU} / \mathrm{mL}\right), 60 \%$ reduction $\left(1.65 \times 10^{5}\right.$ $\mathrm{PFU} / \mathrm{mL}), 65 \%$ reduction $\left(1.47 \times 10^{5} \mathrm{PFU} / \mathrm{mL}\right)$, and $85 \%$ reduction $\left(0.63 \times 10^{5} \mathrm{PFU} / \mathrm{mL}\right)$ were observed when cells were treated with $0.25,0.50,0.75$, and $1 \mu \mathrm{M}$ of YM- 01 , respectively (Fig. 11). This further confirms the role of HSC 70 as a putative CHIKV receptor in C6/36 cells.

\section{Discussion}

For any cell surface molecule to qualify as a virus receptor it has to be located on the cell surface, interact with viral proteins, and anti-receptor antibodies or soluble receptors have to inhibit viral infection. CHIKV infection of $66 / 36$ cells was confirmed by IFA (Fig. 1). VOPBA is a classical technique to select physiologically relevant virus binding molecules on host cell membranes and subsequently identify them by mass spectrometry analysis [15, $21]$. Following this approach, a $\sim 70-\mathrm{kDa}$ protein present in the membrane fraction of C6/36 cells was found to interact with CHIKV (Fig. 2). The MALDI-TOF analysis of the $\sim 70-\mathrm{kDa}$ protein exhibited a high degree of homology to HSC 70 protein (Table 1), which has a molecular weight of $\sim 72 \mathrm{kDa}$ (SwissProt). Although there were sev- 
eral other proteins that were detected in the Mascot search analysis, none of them were analyzed further as they were not considered to be bona fide candidates based on the criteria in the algorithmic approach adopted in this study.

A series of experiments were performed to demonstrate the localization of HSC 70 on the C6/36 cell surface. A Western blot analysis of the membrane and the cytoplasmic protein preparations of $\mathrm{C} 6 / 36$ cells probed with anti-HSC 70 antibody indicated the presence of HSC 70 in the cytosol as well as membrane protein fractions (Fig. 6). Immunofluorescence assay using anti-HSC 70 antibody performed on nonpermeabilized cells revealed that HSC 70 protein was expressed on the cell surface of C6/36 cells (Fig. 7). Even though HSC 70 does not have an export signal sequence, it has been demonstrated on the surface of various cell types such as Hep2, BHK 21, MA 104, Caco-2, and C6/36 [22, 23].
Further, flow cytometry showed that the mean fluorescence for HSC 70 protein was higher in CHIKV-infected cells at $24 \mathrm{~h}$ PI compared to uninfected cells at the same time point (Fig. 8). Interestingly, there was a progressive drop in the fluorescence intensity at 48 and $72 \mathrm{~h}$ PI. Proteomics profiling of $\mathrm{CHIKV}$-infected $\mathrm{C} 6 / 36$ cells also revealed a similar pattern of HSC 70 protein expression wherein an increase was noted in cells at $24 \mathrm{~h}$ PI followed by a reduction during 48 and $96 \mathrm{~h}$ PI [24]. An earlier study on Japanese encephalitis virus-infected Neuro2a cells also reported a reduction of the surface fluorescence for Hsp 70 after $48 \mathrm{~h}$ compared to $24 \mathrm{~h}$ PI [15].

The lateral mobility of most receptor molecules in the plasma membrane is known to allow the formation of a local microdomain rich in receptors under the bound virus where the composition and properties differ from those in the surrounding membrane [25]. This in turn

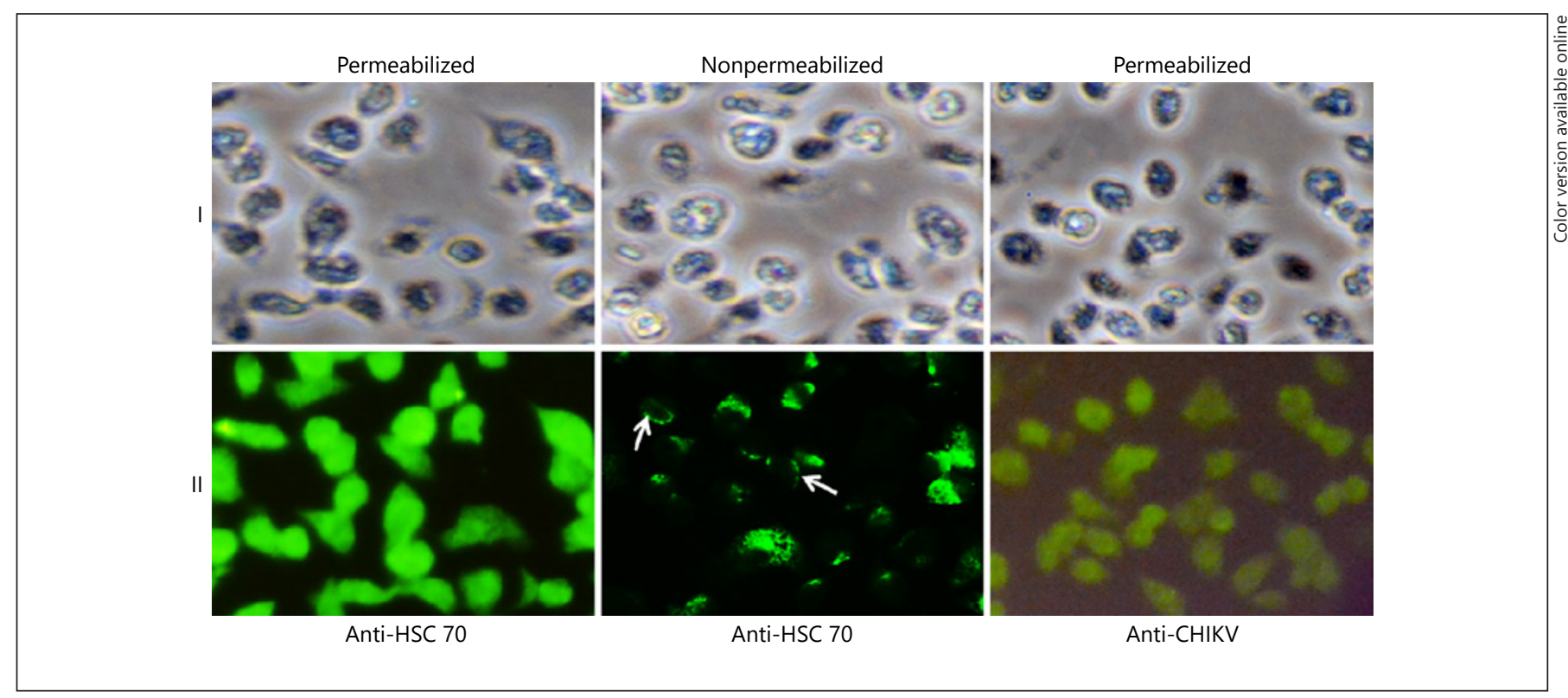

Fig. 7. Localization of HSC 70 on C6/36 cells by indirect immunofluorescence assay (IFA). IFA using anti-HSC 70 antibody was performed with permeabilized or nonpermeabilized cells. AntiCHIKV antibody was used as negative antibody control. Panel I represents bright field phase contrast microscopic images and panel II represents the fluorescence images. Note that nonpermeabilized cells were also positive for HSC 70 (white arrows).
Fig. 8. Cell surface expression of HSC 70 on C6/36 cells analyzed by flow cytometry. Anti-HSC 70 antibody and FITC-conjugated secondary antibody were used for probing. a Side scatter area (SSC-A9) plot of C6/36 cells is depicted in (panel i). Cells were either mock infected (panels ii and iii: uninfected control) or infected with CHIKV (multiplicity of infection of 1) and analyzed at 24 $\mathrm{h}$ (panel iv), $48 \mathrm{~h}$ (panel v), and $72 \mathrm{~h}$ post-infection (PI) (panel vi).
Background fluorescence obtained with C6/36 cells is depicted in b. Note that HSC 70 cell surface fluorescence increases at $24 \mathrm{~h} \mathrm{PI}$ compared to uninfected cells. Thereafter there is a decrease in fluorescence intensity at 48 and $72 \mathrm{~h} \mathrm{PI}$. b Overlap of the scatter plot of all the fluorescence. c HSC 70 expression on C6/36 cell surface at different time points.

(For figure see next page.) 
a
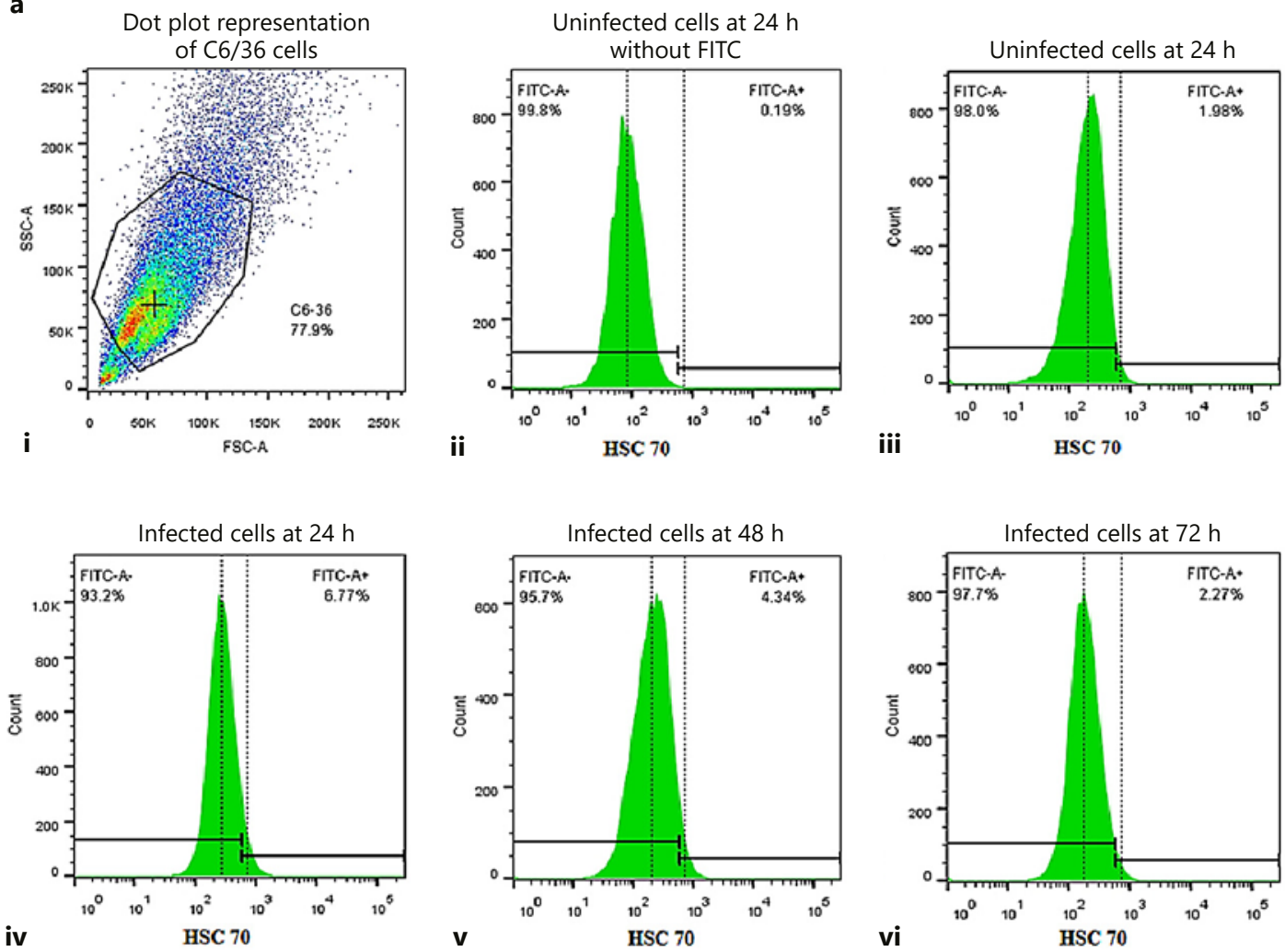

b

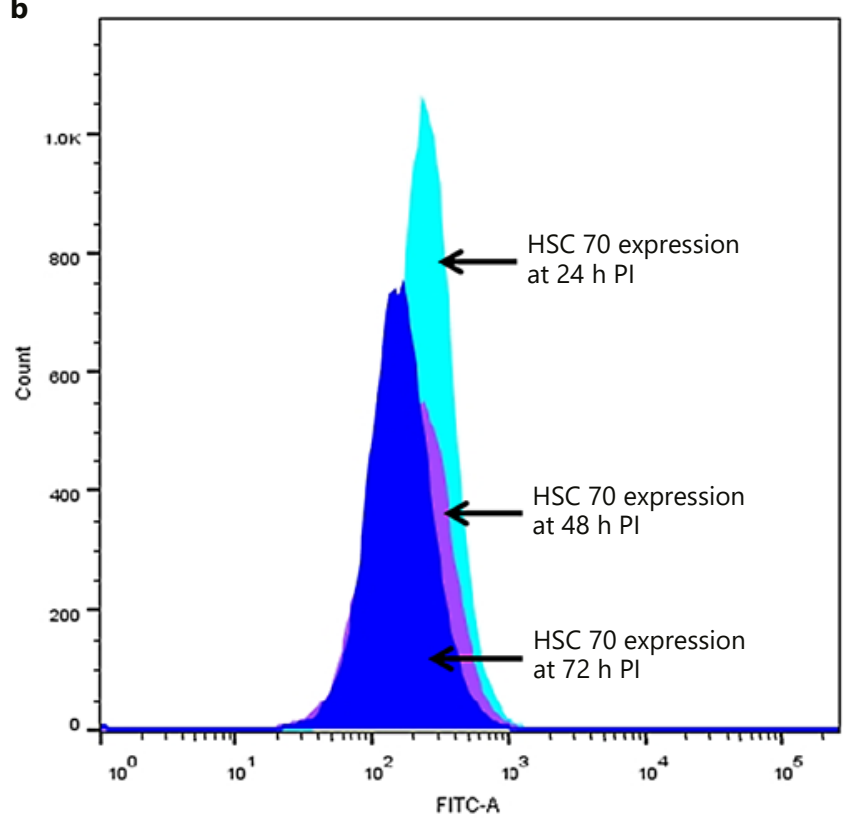

C

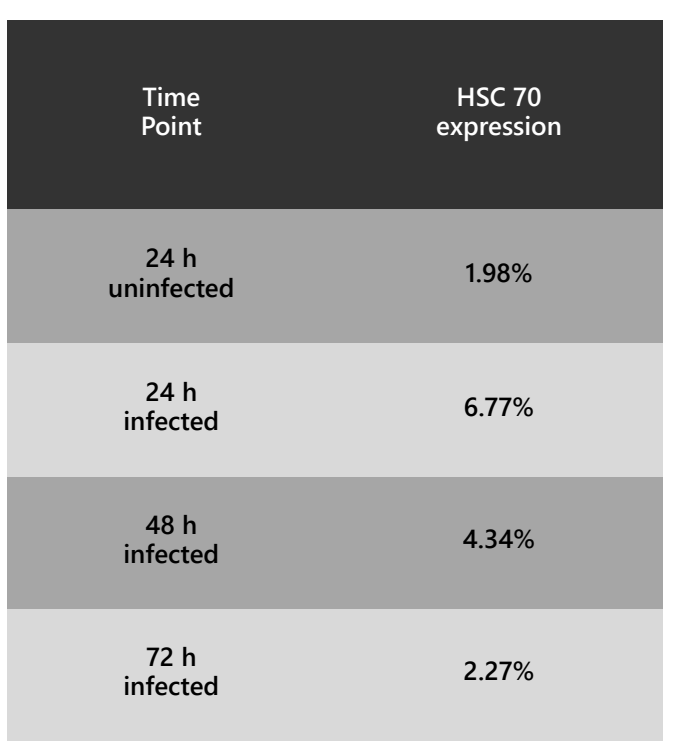

Role of HSC 70 as a Putative CHIKV Receptor on the Surface of C6/36 Cells
Intervirology 2017;60:247-262

DOI: $10.1159 / 000489308$ 
Fig. 9. Depletion of HSC 70 using quercetin. a Immunofluorescence assay using anti-HSC 70 antibody as control and quercetin-treated C6/36 cells. Note the marked reduction in HSC 70 fluorescence in quercetin-treated cells compared to untreated ones. No morphological change was observed in quercetin-treated cells by bright field microscopy. b Quercetin-treated C6/36 cells were infected with CHIKV (multiplicity of infection of 1) and plaque assay was performed using the infectious cell fluid collected $48 \mathrm{~h}$ post-infection. Appropriate controls were included. c Graphical representation of the plaque reduction assay results obtained with quercetin-treated cells. Note the significant reduction in the number of plaques obtained compared to untreated cells.

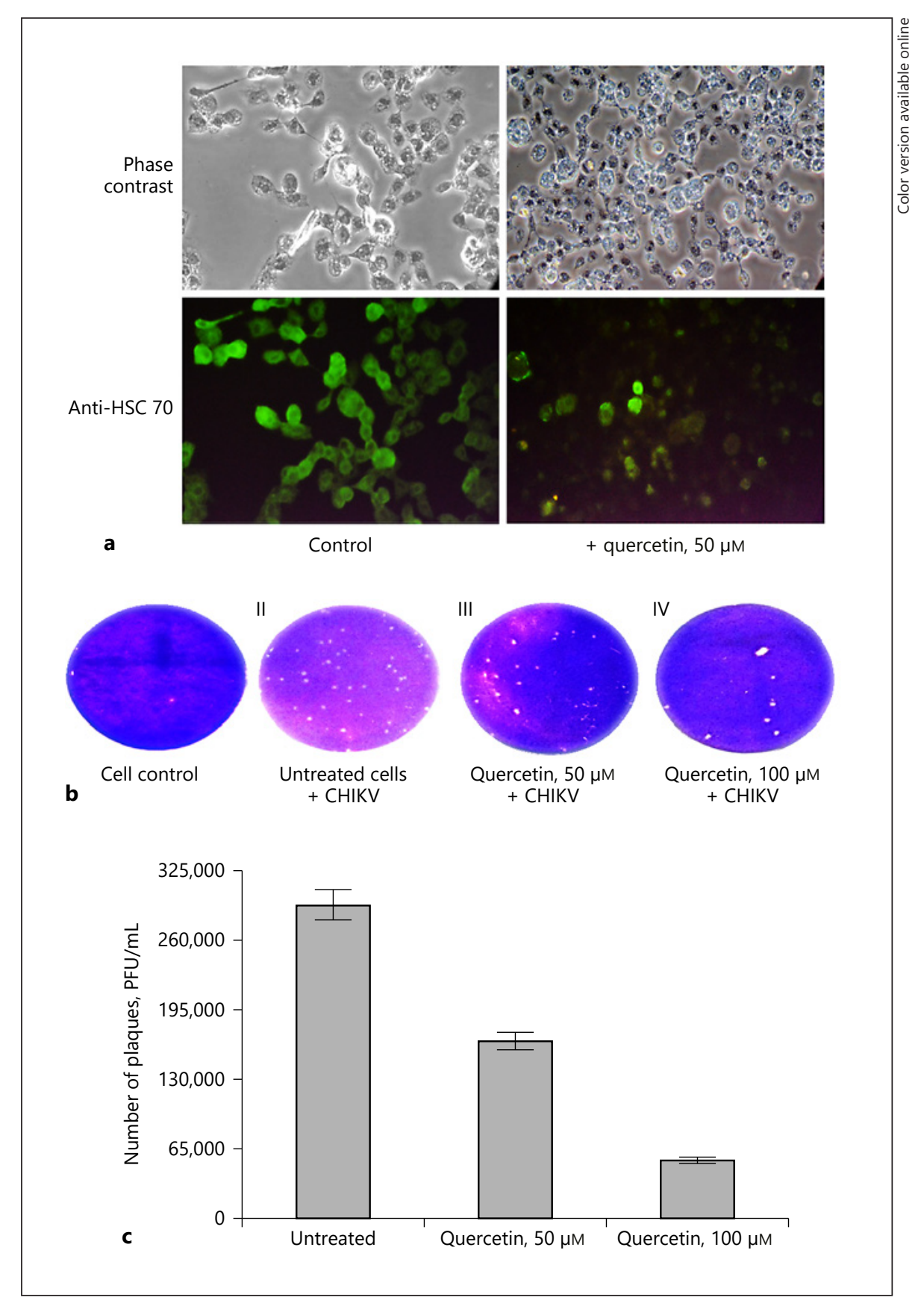

gives rise to a possibility of receptor clustering on the cell membrane at $24 \mathrm{~h}$ which reduces considerably at later time points when most of the cells get infected. The results therefore re-confirmed the presence of HSC 70 on the C6/36 cell surface and its involvement with CHIKV entry during infection.

After demonstrating that HSC 70 is present on the surface of C6/36 cells, the interaction of cell surface HSC 70 with CHIKV protein was studied by Co-IP (pull-down) assay. The Western blot analysis of the immunoprecipitated protein complex demonstrated the presence of CHIKV envelope protein (Fig. 5). Further, anti-HSC 70 antibody competitively inhibited CHIKV entry into C6/36 cells in a dose-dependent manner as confirmed by IFA and plaque reduction experiments (Fig. 3, 4). The inhibition was specific as actin antibody at the same dilu- 
Fig. 10. Infection inhibition assay using YM-01, an allosteric inhibitor of HSC 70 immunofluorescence study. C6/36 cells were pre-treated with different dilutions of YM-01 (as indicated) for $6 \mathrm{~h}$ and then infected with CHIKV (multiplicity of infection of 1). a Phase contrast microscopic images. b Results obtained in the immunofluorescence assay. CHIKV antigen was detected in the cells $48 \mathrm{~h}$ post-infection. Note the reduction of fluorescence staining for CHIKV antigen in the cells incubated with YM-01 (b III and IV) compared to controls (b II and V).

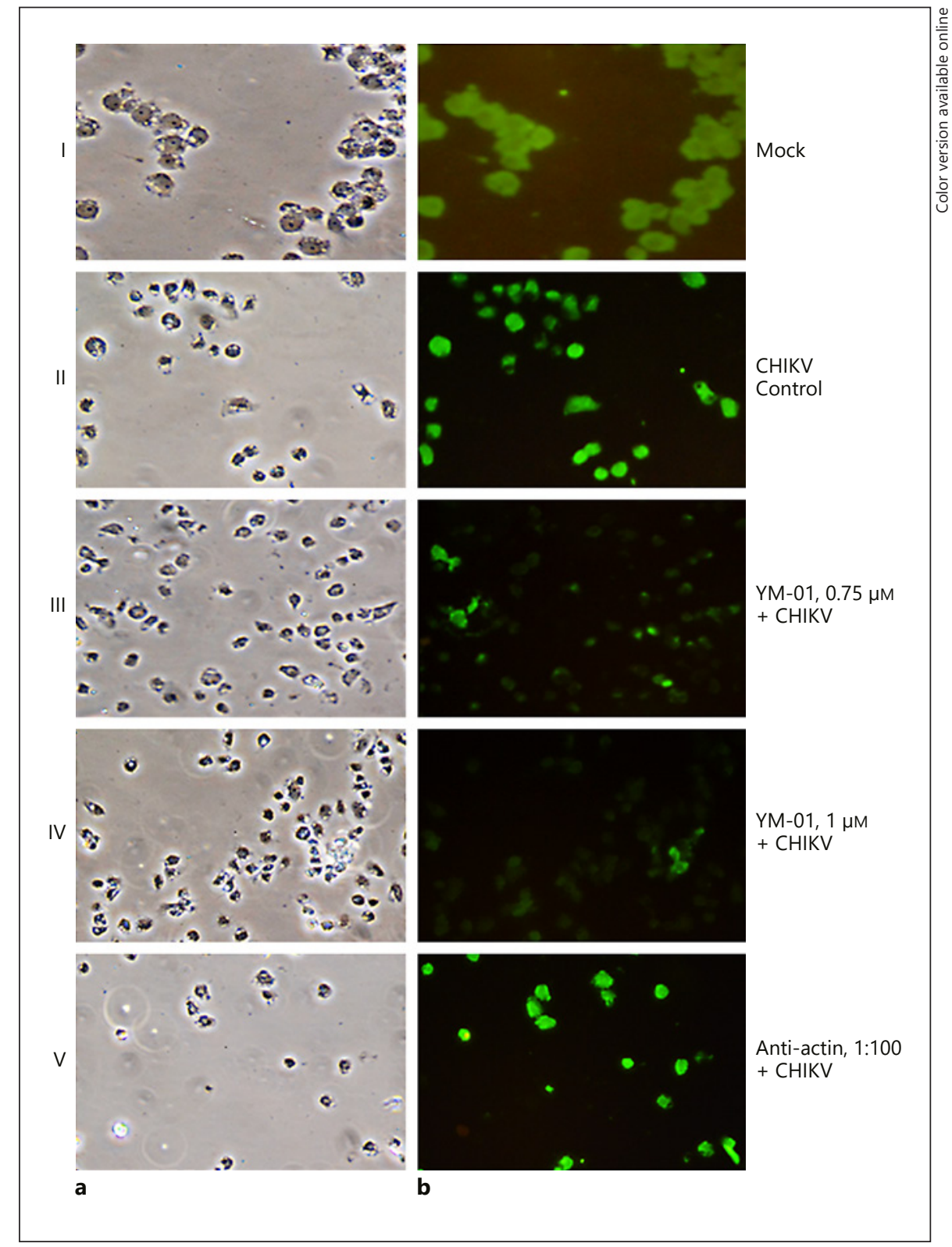

tion did not show any infection inhibition. These results therefore suggest that HSC 70 is crucial for viral attachment/entry into C6/36 cells.

Quercetin, a flavonoid, is an inhibitor of heat shock protein synthesis [26]. C6/36 cells treated with quercetin led to a depletion of cell surface HSC 70 (Fig. 9) as observed by IFA. A reduction in the number of plaques obtained with CHIKV-infected C6/36 cells pre-treated with quercetin compared to those obtained with untreated cells confirmed that HSC 70 on C6/36 cell surface is indeed required for CHIKV infection (Fig. 9). Additionally, cells treated with an allosteric inhibitor of HSC 70, YM01, prior to CHIKV infection exhibited a dose-dependent infection inhibition by IFA and plaque assay experiments, thereby reiterating the role of HSC 70 during CHIKV infection (Fig. 10, 11). Previous studies have shown that treatment of human hepatoma cells with nontoxic concentrations of YM-01 significantly reduced hepatitis C virus yield [18]. The heat shock protein $70-\mathrm{kDa}$ (Hsp 70) family is ubiquitously synthesized in almost all species and consists of phylogenetically conserved molecules which function as molecular chaperones and play critical 
Fig. 11. Infection inhibition assay using YM-01, an allosteric inhibitor of HSC 70 - plaque reduction assay. a C6/36 cells were pre-treated for $6 \mathrm{~h}$ with different dilutions of YM-01 (as indicated) followed by infection with CHIKV (multiplicity of infection of 1). The plaque assay was performed on Vero cells using the infectious cell fluid collected $48 \mathrm{~h}$ post-infection. Appropriate controls were included. b Graphical representation of the plaque reduction assay results obtained with YM-01-treated cells. Note the significant reduction in the number of plaques obtained compared to untreated cells.

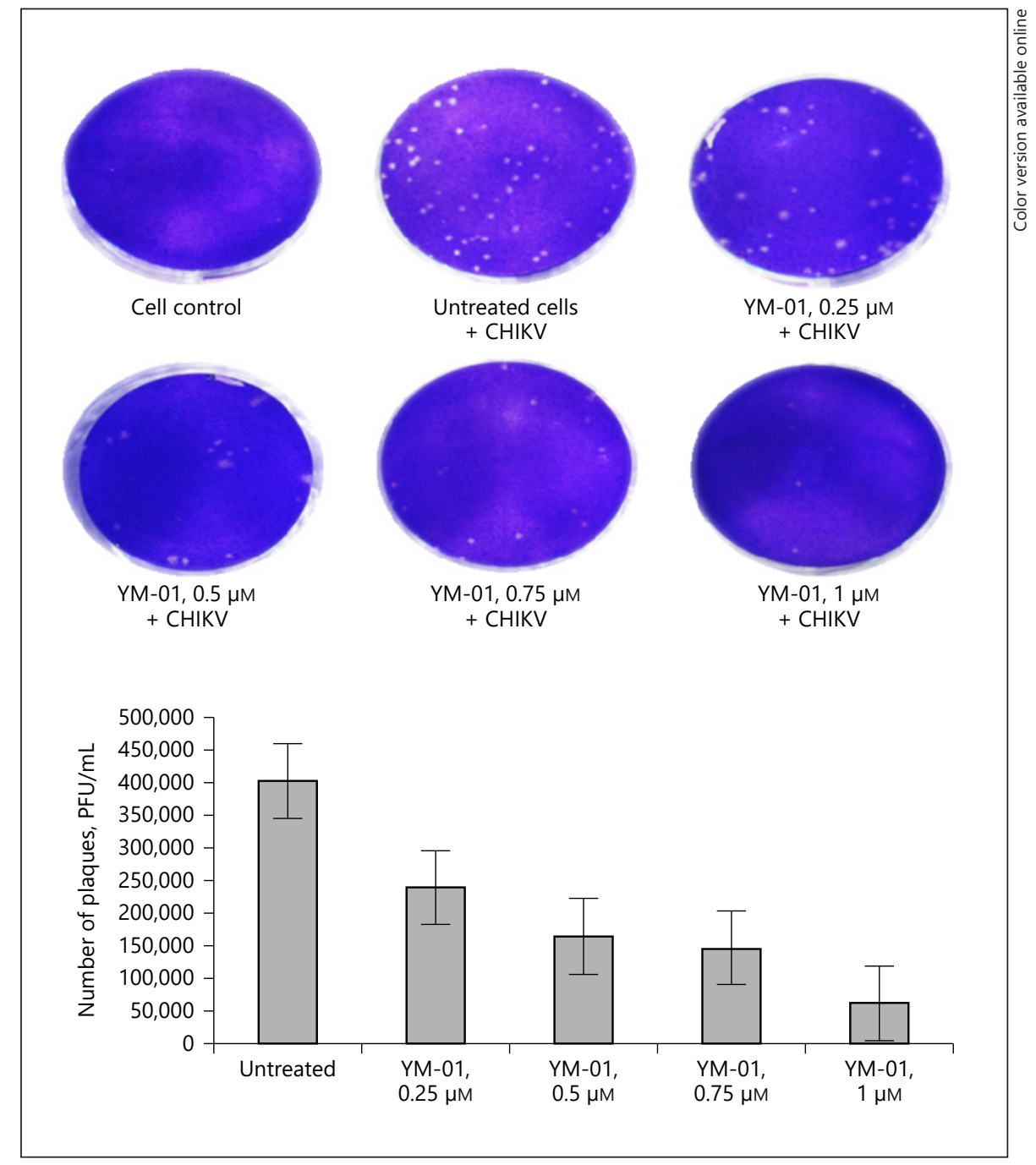

roles in protein folding and trafficking in all eukaryotic cells. Within the Hsp 70 family, Hsp 70 genes are usually inducible whereas HSC 70 genes are mainly constitutive and usually expressed in the absence of stress [27]. Heat shock proteins help to protect cells from a wide array of stresses like elevated temperature and infection [28]. As an intracellular polypeptide, Hsp 70 can be exposed on the plasma membrane and/or released into the circulation $[29,30]$. A wide array of cellular functions has been attributed to HSC 70, mostly through its cooperation with co-chaperones. The role of HSC 70 as a clathrinuncoating ATPase during clathrin-mediated endocytosis has been widely studied. Additionally, HSC 70 plays a crucial role in protein folding, protein degradation, cellular protein folding, and autophagy [31]. HSC 70 protein, present on the surface of different cells, has been implicated as a receptor for different viruses. The functional rotavirus receptor is a complex of several cell surface molecules that include HSC 70 [22]. Dengue, a flavivirus, was reported to interact with the HSC 70 protein among other housekeeping proteins for its entry into mosquito cells [32]. Further, HSC 70 has been proposed as a penetration receptor mediating Japanese encephalitis virus entry into C6/36 cells [23].

Earlier studies have reported that CHIKV exploits housekeeping molecules such as actin, HSP70, and STAT2 to establish infection in the mammalian cells [33]. However, the role of these proteins as putative CHIKV receptors was not ascertained; instead the authors reported that CHIKV interacts with these proteins to establish infection in mammalian cells. In a separate study, prohibitin was identified as a CHIKV receptor on human microglial 
cells (CHME-5) [11]. Although CHIKV is transmitted by Aedes sp. mosquitoes, until recently few studies have been directed towards identification of virus receptors on mosquito cells. A combined approach consisting of VOPBA and mass spectroscopy identified ATPS $\beta$, a component of the mitochondrial F1-Fo ATP synthase, as a CHIKV binding protein capable of mediating virus entry into $\mathrm{C} 6 / 36$ cells [12]. The infection inhibition assay performed by pre-treating C6/36 cells with anti-ATPS $\beta$ antibodies prior to CHIKV infection, followed by flow cytometry, demonstrated a maximal infection inhibition of $30 \%$. The authors attributed this not so significant infection inhibition to the anti-(human) ATPS $\beta$ used in their study, which perhaps did not fully block the (insect)-ATPS $\beta$ CHIKV E2 protein interaction. Further, the Co-IP experiment with $\mathrm{C} 6 / 36$ protein-CHIKV immunocomplex, incubation with anti-ATPS $\beta$ antibody, followed by Western blot and secondary incubation with anti-CHIKV E2 antibody, demonstrated the presence of CHIKV in the immunocomplex. However, the presence of ATPS $\beta$ in the immunocomplex could not be confirmed during the reverse Co-IP experiment [12]. ATPS $\beta$ was therefore reported as an important player in the CHIKV infection of mosquito cells indicative of a "conserved virus-arthropod interaction."

Viruses have been reported to variably employ only a single receptor to infect their target cells or exploit several alternative cell surface proteins to initiate their replication in different cell lines or to enter the same cell type [34]. Additionally, viruses have also been reported to require multiple cell surface receptors to enter host cells
[35]. The concept of multiple cell surface molecules forming a receptor complex to facilitate the entry of a virus, rather than a single receptor molecule, has been widely studied. The functional rotavirus receptor was reported to be a complex of several cell surface molecules that also include HSC 70 [22]. Similarly, human T-cell lymphotropic virus type 3 (HTLV-3) and dengue employs a complex of receptor molecules to bind to primary T lymphocytes and human cells $[36,37]$.

As evident from the infection inhibition experiments performed by pre-incubating C6/36 cells with anti-HSC 70 antibodies in the present study, the dose-dependent infection inhibition was not absolute. Further experiments can therefore reveal whether CHIKV utilizes a receptor complex to enter C6/36 cells. However, the findings in the present study clearly substantiate a crucial role of HSC 70 as a putative CHIKV receptor on the surface of $\mathrm{C} 6 / 36$ cells.

\section{Acknowledgments}

The authors acknowledge funding support from the Department of Biotechnology, Government of India (102/IFD/ SAN/5323/2012-2013, dated March 15, 2013). Fellowship support from the Council of Scientific and Industrial Research, Government of India, to A.G. (Ref. No. 19-12/2010(i) EU-IV, dated June $28,2011)$ is also acknowledged.

\section{Disclosure Statement}

The authors have no conflicts of interest to declare.

\section{References}

1 Strauss JH, Rumenapf T, Weir RC,Kuhn RJ, Wang KS, Strauss EG: Cellular Receptors for Alphaviruses. Cold Spring Harbor Monograph Series, Cold Spring Harbor Laboratory, Cold Spring Harbor, USA, 1994, vol 28, pp 141-164.

2 Schneider-Schaulies J: Cellular receptors for viruses: links to tropism and pathogenesis. J Gen Virol 2000;81:1413-1429.

3 Wang KS, Kuhn RJ, Strauss EG, Ou S, Strauss $\mathrm{JH}$ : High-affinity laminin receptor is a receptor for Sindbis virus in mammalian cells. J Virol 1992;66:4992-5001.

4 Robinson MC: An epidemic of virus disease in Southern Province, Tanganyika territory, in 1952-1953. Trans R Soc Trop Med Hyg 1955;49:28-32.

5 Petersen LR, Powers AM: Chikungunya: epidemiology. F1000Res 2016;5:F1000 Faculty Rev-82.
6 Pialoux G, Gaüzère BA, Jauréguiberry S, Strobel M: Chikungunya, an epidemic arbovirosis. Lancet Infect Dis 2007;7:319-327.

7 Khan AH, Morita K, del Carmen Parquet M, Hasebe F, Mathenge EG, Igarashi A: Complete nucleotide sequence of Chikungunya virus and evidence for an internal polyadenylation site. J Gen Virol 2002;83:3075-3084.

8 Schwartz O, Albert ML: Biology and pathogenesis of Chikungunya virus. Nat Rev Microbiol 2010;8:491.

9 Bordi L, Caglioti C, Lalle E, Castilletti C, Capobianchi MR: Chikungunya and its interaction with the host cell. Curr Trop Med Rep 2015;2:22-29.

10 Kielian M: Structural biology: an alphavirus puzzle solved. Nature 2010;468:645-646.
11 Wintachai P, Wikan N, Kuadkitkan A, Jaimipuk T, Ubol S, Pulmanausahakul R, Auewarakul P, Kasinrerk W, Weng WY, Panyasrivanit $\mathrm{M}$, Paemanee A: Identification of prohibitin as a Chikungunya virus receptor protein. J Med Virol 2012;84:1757-1770.

12 Fongsaran C, Jirakanwisal K, Kuadkitkan A, Wikan N, Wintachai P, Thepparit C, Ubol S, Phaonakrop N, Roytrakul S, Smith DR: Involvement of ATP synthase $\beta$ subunit in Chikungunya virus entry into insect cells. Arch Virol 2014;159:3353-3364.

13 Kumar A, Mamidi P, Das I, Nayak TK, Kumar S, Chhatai J, Chattopadhyay S, Suryawanshi AR, Chattopadhyay S: A novel 2006 Indian outbreak strain of Chikungunya virus exhibits different pattern of infection as compared to prototype strain. PLoS One 2014;9:e85714.
Role of HSC 70 as a Putative CHIKV

Receptor on the Surface of C6/36 Cells
Intervirology 2017;60:247-262

DOI: $10.1159 / 000489308$ 
14 Reddy V, Ravi V, Desai A, Parida M, Powers AM, Johnson BW: Utility of IgM ELISA, TaqMan real-time PCR, reverse transcription PCR, and RT-LAMP assay for the diagnosis of Chikungunya fever. J Med Virol 2012;84: 1771-1778.

15 Das S, Laxminarayana SV, Chandra N, Ravi V, Desai A: Heat shock protein 70 on Neuro2a cells is a putative receptor for Japanese encephalitis virus. Virology 2009;385:47-57.

16 Das S, Ravi V, Desai A: Japanese encephalitis virus interacts with vimentin to facilitate its entry into porcine kidney cell line. Virus Res 2011;160:404-408.

17 Shevchenko A, Tomas H, Havlis J, Olsen JV, Mann M: In-gel digestion for mass spectrometric characterization of proteins and proteomes. Nat Protoc 2007;1:2856-2860.

18 Khachatoorian R, Riahi R, Ganapathy E, Shao $H$, Wheatley NM, Sundberg C, Jung CL, Ruchala P, Dasgupta A, Arumugaswami V, Gestwicki JE: Allosteric heat shock protein 70 inhibitors block hepatitis $C$ virus assembly. Int J Antimicrob Agents 2016;47:289-296.

19 Aghdassi A, Phillips P,Dudeja V, Dhaulakhandi D, Sharif R, Dawra R, Lerch MM, Saluja A: Heat shock protein 70 increases tumorigenicity and inhibits apoptosis in pancreatic adenocarcinoma. Cancer Res 2007;67:616-625.

20 Abisambra J, Jinwal UK, Miyata Y, Rogers J, Blair L, Li X, Seguin SP, Wang L, Jin Y, Bacon J, Brady S: Allosteric heat shock protein 70 inhibitors rapidly rescue synaptic plasticity deficits by reducing aberrant tau. Biol Psychiatry 2013;74:367-374

21 Salas-Benito JS, Del Angel RM: Identification of two surface proteins from C6/36 cells that bind dengue type 4 virus. J Virol1997;71: 7246-7252.
22 Guerrero CA, Bouyssounade D, Zárate S, Iša P, López T, Espinosa R, Romero P, Méndez E, López S, Arias CF: Heat shock cognate protein 70 is involved in rotavirus cell entry. J Virol 2002;76:4096-4102.

23 Ren J, Ding T, Zhang W, Song J, Ma W: Does Japanese encephalitis virus share the same cellular receptor with other mosquito-borne flaviviruses on the $\mathrm{C} 6 / 36$ mosquito cells? $\mathrm{Vi}$ rol J 2007;4:83

24 Lee RC, Chu JJ: Proteomics profiling of chikungunya-infected Aedes albopictus C6/36 cells reveal important mosquito cell factors in virus replication. PLOS Negl Trop Dis 2015; 9:e0003544.

25 English TJ, Hammer DA: The effect of cellular receptor diffusion on receptor-mediated viral binding using Brownian adhesive dynamics (BRAD) simulations. Biophys J 2005;88: 1666-1675.

26 Elia G, Santoro MG: Regulation of heat shock protein synthesis by quercetin in human erythroleukaemia cells. Biochem J 1994;300: 201-209.

27 Yamashita M, Hirayoshi K, Nagata K: Characterization of multiple members of the HSP70 family in platyfish culture cells: molecular evolution of stress protein HSP70 in vertebrates. Gene 2004;336:207-218.

28 Morano KA, Grant CM, Moye-Rowley WS: The response to heat shock and oxidative stress in Saccharomyces cerevisiae. Genetics 2012;190:1157-1195.

29 Takayama S, Xie Z, Reed JC: An evolutionarily conserved family of Hsp70/Hsc70 molecular chaperone regulators. J Biol Chem 1999;274:781-786.
30 Qu B, Jia Y, Liu Y, Wang H, Ren G, Wang H: The detection and role of heat shock protein 70 in various nondisease conditions and disease conditions: a literature review. Cell Stress Chaperones 2015;20:885-892.

31 Stricher F, Macri C, Ruff M, Muller S: HSPA8/ HSC70 chaperone protein: structure, function, and chemical targeting. Autophagy 2013;9:1937-1954.

32 Paingankar MS, Gokhale MD, Deobagkar DN: Dengue-2-virus-interacting polypeptides involved in mosquito cell infection. Arch Virol 2010;155:1453-1461.

33 Paingankar MS, Arankalle VA: Identification of Chikungunya virus interacting proteins in mammalian cells. J Biosci 2014;39:389-399.

34 Baranowski E, Ruiz-Jarabo CM, Pariente N, Verdaguer N, Domingo E: Evolution of cell recognition by viruses: a source of biological novelty with medical implications. Adv Virus Res 2003;62:19-11.

35 Grove J, Marsh M: The cell biology of receptor-mediated virus entry. J Cell Biol 2011;195: 1071-1082.

36 Jones KS, Huang YK, Chevalier SA, Afonso PV, Petrow-Sadowski C, Bertolette DC, Gessain A, Ruscetti FW, Mahieux R: The receptor complex associated with human T-cell lymphotropic virus type 3 (HTLV-3) Env-mediated binding and entry is distinct from, but overlaps with, the receptor complexes of HTLV-1 and HTLV-2. J Virol 2009;83:52445255.

37 Reyes-del Valle J, Chávez-Salinas S, Medina F, del Angel RM: Heat shock protein 90 and heat shock protein 70 are components of dengue virus receptor complex in human cells. J Virol 2005;79:4557-4567. 